\title{
The Value of Primordial Prevention in the Obesity Epidemic and Related Comorbidities
}

\author{
Samantha Buls ${ }^{1 *}$ and Mercedes Sotos-Prieto ${ }^{1,2}$
}

${ }^{1}$ Division of Food and Nutrition Sciences, School of Applied Health Sciences and Wellness, Ohio University, Athens, USA

${ }^{2}$ Department of Nutrition and Department of Environmental Health, Harvard T.H. Chan School of Public Health, Boston, MA, and Division of Occupational Medicine, Cambridge Health Alliance/Harvard Medical School, USA

*Corresponding author: Samantha Buls, Division of Food and Nutrition Sciences, School of Applied Health Sciences and Wellness, Ohio University, Athens, USA. Tel: 2402850933; E-mail: sb400211@ohio.edu

Received date: Jul 21, 2017; Accepted date: Sep 25, 2017; Published date: Oct 03, 2017

Citation: Buls S, Sotos-Prieto M (2017) The value of Primordial Prevention in the Obesity Epidemic and Related Comorbidities. J Obes Eat Disord 3:1. doi: 10.21767/2471-8203.100032

Copyright: (C2017 Buls S, et al. This is an open-access article distributed under the terms of the Creative Commons Attribution License, which permits unrestricted use, distribution, and reproduction in any medium, provided the original author and source are credited.

\section{Short Communication}

Despite an overall increase in public health awareness, the prevalence of obesity remains epidemically high. Worldwide, over half a billion people are currently classified as obese (body mass index $[\mathrm{BMI}] \geq 30 \mathrm{~kg} / \mathrm{m}^{2}$ ), and it is estimated that over $40 \%$ of the U.S population will be obese by the year 2030 [1]. These statistics are of serious concern because of the recognized relationship between obesity and chronic disease, specifically cardiovascular disease (CVD) being the number one cause of death in the United States [2].

Even in the absence of other cardiac related comorbidities, excess adipose tissue often induces dyslipidaemia, hypertension and glucose intolerance, all indicative of metabolic syndrome [3]. While each of these components is known to increase CVD risk independently, the combination of these markers and the presence of metabolic syndrome itself is associated with a significant long-term risk of CVD [4].

Strong evidence suggests that healthy lifestyle habits can influence CVD risk factors [5]. For example, when observing more than 80,000 nurses, over $90 \%$ of diabetes mellitus cases, $57 \%$ of hypertension cases, and $40 \%$ of hypercholesterolemia cases were attributed to poor lifestyle factors [6]. Research has also showed that a combination of at least three low risk lifestyle factors and a BMI between 18.5-22.4 is associated with the lowest risk of CVD $(0.37,0.29$ to 0.46$)$ mortality, when compared with those with a BMI between 22.5-24.9 and none of the four low-risk lifestyle factors [7]. This emphasizes the importance of maintaining a healthy weight and the prevention of clinical risk factor development, recognizing the value of primordial prevention.

Primordial prevention is defined as the prevention of the risk factors themselves, before the individual is negatively affected by the symptoms [8]. This is often thought of as radical, especially in young patients who don't currently exhibit concerning biomarkers. Primordial prevention differs from primary prevention in that the emphasis is on early dietary and lifestyle modifications to prevent the risk factors in the first place. If these risk factors are proven to lead to the onset of disease, why would health providers not want to prevent them from occurring in the first place? This is especially true when considering the alarming long-term risk that the obese population faces for developing CVD despite a perceived low short-term risk [4].

Currently, there are numerous risk prediction tools that include in their assessment clinical risk factors such as blood pressure, and blood lipids to estimate an individual's short term (i.e., 10-years) risk of CVD. For individuals with a high risk based on these factors, it is common practice to attempt to decrease risk pharmacologically [9]. However, individuals with a low short term risk but elevated long term risk may benefit from alternative methods of risk factor management. In addition, the fact that drug therapy is usually prescribed when short term risk is high ( $>7.5 \%$ over 10 years) has led to hypertension, diabetes mellitus, and hyperlipidemia becoming three of the top diagnoses related to direct health expenditures in the U.S. [10]. Long term risk factor control plays a key role in the prevention of CVD and is rarely talked about in the clinical setting which may be problematic because short term risk, while clinically important, often underestimate risk burden in young adults $(<50$ years) [11]. For example, the lifetime risk of CVD in adults with $\geq$ 2 risk factors at age 55 (50\% in men and $29 \%$ in women) was 3fold greater than the risk in adults with optimal risk factor status at age 55 [12]. Therefore, an individual's overall cardiovascular risk may be best estimated by a combination of short and longterm (30-year) risk assessment.

Long term CVD risk can be reduced by implementing and maintaining primordial prevention strategies to create a normalized metabolic profile [13]. Young adults who are able to maintain a low CVD risk profile into middle age drastically reduce, if not eliminate, their long term risk for life threatening CVD events [14]. If the majority of the population were able to reach middle age with a low CVD risk profile, the vast majority of expected CVD related deaths could be prevented [14]. Yet the current focus has been on primary prevention or short term risk prevention, and over the last decade less than $6 \%$ of the US population maintained a low risk profile, drastically reducing life expectancy by as many as 10 years $[14,15]$.

The first step in effective primordial prevention is recognizing long term risk and encouraging lifestyle modifications. Even 
minor improvements to diet and physical activity levels have been proven to significantly lower blood pressure, improve lipid profile, and affect the efficiency of glucose metabolism and longevity $[3,16,17]$. However, primordial prevention is often forgotten and physicians spend little time advising patients on the importance of long-term health and lifestyle behaviours $[18,19]$.

Health professionals need to start recognizing long term risk, and discussing the importance of primordial prevention with patients. Created by a team at the Harvard T.H. Chan School of Public Health, The Healthy Heart Score is an online 20-year risk prediction tool with the potential to be utilized in the clinical setting to catalyse the conversation. The Healthy Heart Score uses modifiable lifestyle factors (diet, physical activity, alcohol intake, smoking, and body weight) to estimate 20-years risk of CVD. The model has been validated [7] with data from large cohorts that consist primarily of non-Hispanic white, middleaged women and men and performs best among individuals without baseline CVD risk factors. Previous findings using the Healthy Heart Score showed that women in the highest quintile (poorest behaviour's) of the Healthy Heart Score had a predicted 18.01 (14.39-22.72) higher risk of diabetes, $5.00(4.56,5.45)$ of hypertension, $2.57(2.40,2.75)$ of hypercholesterolemia, and 52.75 (95\% Cl: $33.75-82.45)$ of all 3 risk factors combined, compared to women in the lowest quintile (healthiest behaviour's) [20]. Researchers are currently collecting qualitative data to better understand the clinical utility of a lifestyle-only risk assessment tool with goal of adding clinical value when used in combination with short term risk models. Preliminary findings suggest that implementing the Healthy Heart Score into the clinical setting would be accepted by patients and could help increase patient motivation to make and maintain lifestyle changes. Many existing comprehensive lifestyle interventions have been successful in changing lifestyle behaviour's resulting in weight loss and other health benefits [10]. The challenge is to achieve low cost, sustainable interventions that can educate patients on healthy behaviour's so that every person many fully engage in their own health care and healthy lifestyle maintenance. Overall identifying and preventing CVD risk in individuals of all ages is of paramount importance. Education is the key to motivating people to make lifestyle and behavioural changes to improve or maintain cardiovascular health and decrease CVD burden

\section{References}

1. Smith KB \& Smith MS (2016) Obesity Statistics. Prim Care 43 121-135.

2. Benjamin EJ, Blaha MJ, Chiuve SE, Cushman M, Das SR, et al. (2017) Heart Disease and Stroke Statistics-2017 Update: A Report From the American Heart Association. Circulation 135: e146-e603.

3. Poirier P, Giles TD, Bray GA, Hong Y, Stern JS, et al. Obesity Committee of the Council on Nutrition, Physical Activity, and Metabolism. (2006) Obesity and cardiovascular disease: pathophysiology, evaluation, and effect of weight loss: an update of the 1997 American Heart Association Scientific Statement on Obesity and Heart Disease from the Obesity Committee of the Council on Nutrition, Physical Activity, and Metabolism. Circulation 113: 898-918.
4. Grundy SM, Cleeman JI, Daniels SR, Donato KA, Eckel RH, et al. \& National Heart, Lung and Blood Institute (2005) Diagnosis and management of the metabolic syndrome: an American Heart Association/National Heart, Lung, and Blood Institute Scientific Statement. Circulation 112: 2735-2752.

5. Sotos-Prieto $M$, Bhupathiraju SN, Mattei J, Fung TT, Li $Y$, et al. (2015) Changes in Diet Quality Scores and Risk of Cardiovascular Disease Among US Men and Women. Circulation 132: 2212-2219.

6. Chomistek, AK, Chiuve SE, Eliassen AH, Mukamal KJ, Willett WC, et al. (2015) Healthy Lifestyle in the Primordial Prevention of Cardiovascular Disease Among Young Women. J Am Coll Cardiol 65: 43-51.

7. Veronese N, Li Y, Manson JE, Willett WC, Fontana L, et al. (2016) Combined associations of body weight and lifestyle factors with all cause and cause specific mortality in men and women: prospective cohort study. BMJ 355: i5855.

8. Weintraub WS, Daniels SR, Burke LE, Franklin BA, Goff DC, et al. \& Council on Clinical Cardiology, and Stroke Council (2011) Value of primordial and primary prevention for cardiovascular disease: a policy statement from the American Heart Association. Circulation, 124: 967-990.

9. Chiuve SE, Cook NR, Shay CM, Rexrode KM, Albert CM, et al. (2014). LifestyleBased Prediction Model for the Prevention of CVD: The Healthy Heart Score. J Am Heart Assoc: Cardiovascular and Cerebrovascular Disease 3: e000954

10. Salami JA, Valero-Elizondo J, Ogunmoroti O, Spatz ES, Rana JS, et al. (2017) Association Between Modifiable Risk Factors and Pharmaceutical Expenditures Among Adults With Atherosclerotic Cardiovascular Disease in the United States: 2012-2013 Medical Expenditures Panel Survey. J Am Heart Assoc 6.

11. Berry JD, Lloyd-Jones DM, Garside DB, Greenland P (2007) Framingham risk score and prediction of coronary heart disease death in young men. Am Heart J 154: 80-86.

12. Wilkins JT, Ning H, Berry J, Zhao L, Dyer AR, et al. (2012) Lifetime risk and years lived free of total cardiovascular disease. JAMA 308: 1795-1801.

13. Magnussen, C. G., Koskinen, J., Juonala, M., Chen, W., Srinivasan, S. R., et al. (2012) A diagnosis of the metabolic syndrome in youth that resolves by adult life is associated with a normalization of high carotid intima-media thickness and type 2 diabetes mellitus risk: the Bogalusa heart and cardiovascular risk in young Finns studies. J Am Coll Cardiol 60: 1631-1639.

14. Lloyd-Jones DM, Leip EP, Larson MG, D'Agostino RB, Beiser A, et al. (2006) Prediction of lifetime risk for cardiovascular disease by risk factor burden at 50 years of age. Circulation 113: 791-798.

15. Capewell S, Ford ES, Croft JB, Critchley JA, Greenlund KJ, et al. (2010) Cardiovascular risk factor trends and potential for reducing coronary heart disease mortality in the United States of America. Bull World Health Organ 88: 120-130.

16. Sotos-Prieto $M$, Bhupathiraju SN, Mattei J, Fung TT, Li Y, et al (2017) Association of Changes in Diet Quality with Total and Cause-Specific Mortality. N Engl J Med 377: 143-153.

17. Johnston CA, Moreno JP, \& Foreyt JP (2014) Cardiovascular Effects of Intensive Lifestyle Intervention in Type 2 Diabetes. Curr Atheroscler Reps 16: 457

18. Mosca L, Linfante AH, Benjamin EJ, Berra K, Hayes SN, et al. (2005) National study of physician awareness and adherence to cardiovascular disease prevention guidelines. Circulation 111: 499-510. 
19. Mosca L, Linfante AH, Benjamin EJ, Berra K, Hayes SN, et al. (2006) National study of physician awareness and adherence to cardiovascular diseases. Circulation 112: 500.

20. Sotos-Prieto M, Mattei J, Hu FB, Chomistek AK, Rimm EB et al. (2016) Association Between a Healthy Heart Score and the
Development of Clinical Cardiovascular Risk Factors Among Women. Circ Cardiovasc Qual Outcomes 9: S77-S85. 